\title{
Article \\ Impacts of Lithium Salts on the Thermal and Mechanical Characteristics in the Lithiated PEO/LAGP Composite Electrolytes
}

\author{
Jeremy Lee ${ }^{1}$, Michael Rottmayer ${ }^{2}$ and Hong Huang ${ }^{1, * \mathbb{D}}$ \\ 1 Department of Mechanical and Materials Engineering, Wright State University, 3640 Colonel Glenn Hwy, \\ Dayton, OH 45435, USA; lee.263@wright.edu \\ 2 Wright-Patterson Air Force Research Laboratory, Electrical Systems Branch, Power and Control Division, \\ Dayton, OH 45433, USA; Michael.Rottmayer@us.af.mil \\ * Correspondence: hong.huang@wright.edu; Tel.: +1-937-7753982
}

Citation: Lee, J.; Rottmayer, M.; Huang, H. Impacts of Lithium Salts on the Thermal and Mechanical Characteristics in the Lithiated PEO/LAGP Composite Electrolytes. J. Compos. Sci. 2022, 6, 12. https:// doi.org/10.3390/jcs6010012

Academic Editor: Francesco Tornabene

Received: 29 November 2021 Accepted: 23 December 2021 Published: 30 December 2021

Publisher's Note: MDPI stays neutral with regard to jurisdictional claims in published maps and institutional affiliations.

Copyright: (C) 2021 by the authors. Licensee MDPI, Basel, Switzerland. This article is an open access article distributed under the terms and conditions of the Creative Commons Attribution (CC BY) license (https:/ / creativecommons.org/licenses/by/ $4.0 /)$.

\begin{abstract}
Lithium batteries utilizing solid-state electrolytes have the potential to alleviate their safety hazard, reduce packaging volume, and enable flexible design. Polymer/ceramic composite electrolytes (CPE) are more attractive because the combination is capable of remedying and/or transcending individual constituent' properties. Recently, we fabricated a series of free-standing composite electrolyte membranes consisting of $\mathrm{Li}_{1.4} \mathrm{Al}_{0.4} \mathrm{Ge}_{1.6}\left(\mathrm{PO}_{4}\right)_{3}$ (LAGP), polyethylene oxide (PEO), and lithium salts. In this study, we characterized thermal and mechanical properties of the $\mathrm{CPEs}$ with two representative lithium salts, i.e., lithium boron fluoride $\left(\mathrm{LiBF}_{4}\right)$ and lithium bis(trifluoromethanesulfonyl)imide (LiTFSI). We found that the type of lithium salt can prevail the LAGP ceramic loadings on altering the key properties. It is observed that LiTFSI, compared with $\mathrm{LiBF}_{4}$, causes more significant reduction in terms of the crystallinity of PEO, melting transition, and mechanical strengths. The differences in these aspects can be ascribed to the interactions between the polymer matrix and anions in lithium salt.
\end{abstract}

Keywords: lithium; electrolyte; thermal; mechanical; composite

\section{Introduction}

Currently, advanced lithium-ion batteries and lithium batteries based on the lithiumsulfur and lithium-oxygen chemistries have been the main foci to meet the ever-increased demands for higher energy density and safety. Solid-state electrolyte, owing to it nonflammable nature, is one logical alternative to the volatile organic liquid electrolyte. In addition to alleviate the thermal runaway hazards, solid electrolytes have potentials to address the issues of continuous deterioration of solid electrolyte interphase (SEI) layer in Li-ion, the dissolution of polysulfides in Li-S, and lithium dendrite growth in Li-Air [1,2] Ceramic lithium-ion conductors and dry polymers solvated with lithium ions have both pros and cons [3,4]. For instance, dry polymer electrolytes are satisfactory in terms of mechanical and thermal properties, but their ambient ionic conductivities are too low $\left(10^{-5}-10^{-7} \mathrm{~S} / \mathrm{cm}\right)$ to be applicable. Most ceramic electrolytes are highly conductive but rigid and brittle. Consequently, they have poor interfacial contact with electrodes, are sensitive to mechanical shock, and are limited in shape configuration design. One of the viable pathways is to combine ceramics and polymers into composite electrolytes that can transcend individual constituent towards achieving electrolytes that are highly conductive, safe, and flexible.

In the composite polymeric electrolyte (CPE) systems, active ceramic fillers are attractive because they act as charge carriers providing extra ion conduction pathway or possible solvation sites rendering increased mobility of lithium ions [5-19]. Most public entities in this area were focused on improving conductivity and electrochemical stability through 
adding active ceramic fillers, although there is a huge disparity in reporting how high the conductivity is improved and how many active fillers are appropriate to maximize the conductivity [7-11]. In the vast CPE formulation, it is noticeable that lithium salts varied from $\mathrm{LiClO}_{4}$ [10-14], $\mathrm{LiPF}_{6}$ [16], $\mathrm{LiBF}_{4}$ [17], $\mathrm{LiSO}_{3} \mathrm{CF}_{3}$ (LiTF) [18], to $\mathrm{LiN}\left(\mathrm{SO}_{2} \mathrm{CF}_{3}\right)_{2}$ (LiTFSI) $[7-9,14,15,19]$. Although there are some reports directly comparing the impacts of lithium salts on the ionic conductivities, there are sparse reports presenting improved mechanical properties and lack of in-depth discussion. We are not aware systematic studies focusing on the impacts of lithium salts on thermal and mechanical properties in a same polymer/ceramic electrolyte setting.

In aprotic liquid electrolytes, the impacts of lithium salts on the conductivities and thermal stabilities have been extensively investigated. $\mathrm{LiClO}_{4}$ is thrown into question when acknowledging its potential safety hazards $[20,21]$. Although $\mathrm{LiPF}_{6}$ was mostly utilized in lithium-ion batteries for its high ionic conductivity and enabling a relatively stable passivation layer, it is highly susceptible to hydrolysis and thermal decomposition [21,22]. $\mathrm{LiBF}_{4}$, having moderate ionic conductivities, is more resistant to hydrolysis and thermal decomposition and exhibits excellent performances at low temperatures $[21,23,24]$. LiTFSI is presently one of the most favorable lithium salts owing to its sufficient ionic conductivity, good thermal stability (up to $300^{\circ} \mathrm{C}$ ), and its remarkable tolerance to hydrolysis [21,25].

We recently developed a processing method and systematically fabricated large-area free-standing solid composite electrolytes based on lithiated polyethylene oxide (PEO) and $\mathrm{Li}_{1+x} \mathrm{Al}_{\mathrm{x}} \mathrm{Ge}_{2-\mathrm{x}}\left(\mathrm{PO}_{4}\right)_{3}$ (LAGP). LAGP is known for its high ionic conductivities $\left(10^{-4} \mathrm{~S} / \mathrm{cm}\right.$ at room temperatures) and good stability with moisture [26-28]. In our previous paper, we have investigated the impacts of LAGP loading on the electrical, thermal, and mechanical characteristics in the PEO/LAGP/LiTFSI composite system [29]. It was observed that increasing LAGP amount up to $60 \mathrm{wt} \%$ slightly increased melting temperature of PEO, significantly increased elastic modulus, reduced strain-to-failure point, but had insignificant impact on yielding strength. Further, it was noticed that these values of the $\mathrm{PEO} / \mathrm{LiTFSI}$ /LAGP series are much lower compared with those of virgin PEO. In order to understand if the observed phenomena reflect a general trend in the presence of LAGP and to explore an alternative lithium salt candidate which has better thermal stability and mechanical strength, we have investigated the $\mathrm{PEO} / \mathrm{LAGP} / \mathrm{LiBF}_{4}$ system. $\mathrm{LiBF}_{4}$ was selected in consideration of its favorable merits in liquid electrolyte and its properties fundamentally distinguished from LiTFSI. In this paper, we present the results of $\mathrm{PEO} / \mathrm{LAGP} / \mathrm{LiBF}_{4}$, in comparison with PEO/LAGP/LiTFSI. Since the polymer matrix and ceramic filler ratio are fixed, the systematic studies render us to exclusively determine the impacts of type of lithium salt on the thermal and mechanical properties. The discussion emphasizes on the aspects of melting transition and mechanical reinforcement differences resulting from the two lithium salts.

\section{Experimental}

\subsection{Fabrication of LAGP/PEO/LiTFSI Composite Membranes}

A series of the PEO/Li-salt/LAGP composite films were fabricated in sequentially increasing weight proportions of LAGP relative to PEO from $20 \mathrm{wt} \%$ to $60 \mathrm{wt} \%$. For the

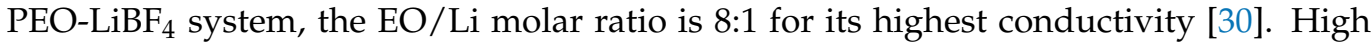
conductivities are reported in the PEO-LiTFSI system when molar ratio between PEO and LiTFSI is in the range of 8:1 to 20:1 [31,32]. In this study, a molar ratio of 20:1 was selected for the ease of fabricating free-standing membranes. Table 1 lists the amount of component and the portion of LAGP in each composite membrane. 
Table 1. The composition of LAGP and Li-salt used to fabricate the PEO/Li-salt/LAGP composite electrolyte membranes.

\begin{tabular}{|c|c|c|c|c|c|}
\hline Specimen Nomination & $\begin{array}{c}\text { wt } \% \text { LAGP } \\
/(\mathrm{LAGP}+\text { PEO })\end{array}$ & $\begin{array}{c}\text { wt } \% \text { LAGP } \\
\text { /Total }\end{array}$ & $\begin{array}{l}\text { vol } \% \text { LAGP } \\
\text { /Total }\end{array}$ & EO:Li Ratio & $\begin{array}{c}\text { wt } \% \text { Li-Salt } \\
\text { /Total }\end{array}$ \\
\hline $\mathrm{PEO}$ & 0.0 & 0.0 & 0.0 & NA & \\
\hline PEO/LiTFSI & 0.0 & 0.0 & 0.0 & 20.0 & 24.5 \\
\hline LiTFSI/LAGP20 & 20.0 & 15.9 & 7.3 & 20.0 & 20.7 \\
\hline LiTFSI/LAGP30 & 30.0 & 24.4 & 11.9 & 20.0 & 18.5 \\
\hline LiTFSI/LAGP50 & 50.0 & 43.0 & 24.1 & 20.0 & 14.0 \\
\hline LiTFSI/LAGP60 & 60.0 & 53.1 & 32.2 & 20.0 & 11.5 \\
\hline $\mathrm{PEO} / \mathrm{LiBF}_{4}$ & 0.0 & 0.0 & 0.0 & 8.0 & 21.0 \\
\hline $\mathrm{LiBF}_{4} / \mathrm{LAGP} 20$ & 20.0 & 16.5 & 6.9 & 8.0 & 17.6 \\
\hline $\mathrm{LiBF}_{4} / \mathrm{LAGP30}$ & 30.0 & 25.2 & 11.3 & 8.0 & 15.7 \\
\hline $\mathrm{LiBF}_{4} / \mathrm{LAGP50}$ & 50.0 & 44.1 & 22.9 & 8.0 & 11.7 \\
\hline $\mathrm{LiBF}_{4} / \mathrm{LAGP}_{60}$ & 60.0 & 54.2 & 30.9 & 8.0 & 9.6 \\
\hline
\end{tabular}

All chemicals are from either Sigma Aldrich or Alfa Aesar, ACS grade, and used without further purification or treatment. $\mathrm{Li}_{1.4} \mathrm{Al}_{0.4} \mathrm{Ge}_{1.6}\left(\mathrm{PO}_{4}\right)_{3}$ was synthesized using lithium carbonate $\left(\mathrm{Li}_{2} \mathrm{CO}_{3}\right)$, aluminum hydroxide $\left(\mathrm{Al}(\mathrm{OH})_{3}\right)$, ammonium dihydrogen phosphate $\left(\mathrm{NH}_{4} \mathrm{H}_{2} \mathrm{PO}_{4}\right)$ and germanium oxide $\left(\mathrm{GeO}_{2}\right)$. The solvent used to dissolve PEO (molecular weight of 400,000) and lithium salt $\left(\mathrm{LiBF}_{4}\right.$ and LiTFSI) is anhydrous acetonitrile (AN). Detailed procedures of synthesizing LAGP and fabricating the composite membranes were elaborated elsewhere $[29,33]$.

\subsection{Thermal and Mechanical Characterizations}

The thermal characteristics of the composite membranes were analyzed using differential scanning calorimetry (DSC 2010, TA Instruments). The specimens with the weight of around $10 \mathrm{mg}$ sealed in an aluminum pan were heated from $25-120{ }^{\circ} \mathrm{C}$ at a rate of $5{ }^{\circ} \mathrm{C} / \mathrm{min}$. The onset and peak melting temperatures as well as the enthalpy of fusion were determined with the help of TA Instruments Universal Analysis software.

The mechanical testing was conducted on a tensionmeter with an automatically controlled translation stage from Bruker with a maximum elongation of $550 \%$. The membranes were punched with an ASTM D638V die and were mounted to the tensionmeter. The strain rate was fixed at $1.05 \%$ per second. All tests were carried out in a dry-room that maintained a moisture level below $0.8 \%$ relative humidity and a constant temperature at $21^{\circ} \mathrm{C}$.

\section{Results and Discussion}

Figure 1a presents a typical free-standing, flexible, pore-free, and crack-free membrane we fabricated, from which specimens were punched for electrical, thermal, and mechanical characterizations. The average thicknesses of the membranes are in the range of 50-75 micrometer depending on the LAGP content. The thickness of each specimen is relatively homogeneous throughout the 4.5 -inch membrane. LAGP particles are homogeneously embedded in the PEO polymer matrix. The sizes of most LAGP particles are in the submicrometer range ( $200 \mathrm{~nm}$ to $600 \mathrm{~nm}$ ). There are a few LAGP agglomerates of a few micrometers. Figure $1 \mathrm{~b}$ exhibit representative SEM image of a composite membrane consisting of $20 \mathrm{wt} \%$ LAGP. With increasing the content of LAGP, the average spacing between LAGP particulates is gradually reduced and the amount of agglomerates tends to increase. 




(a)

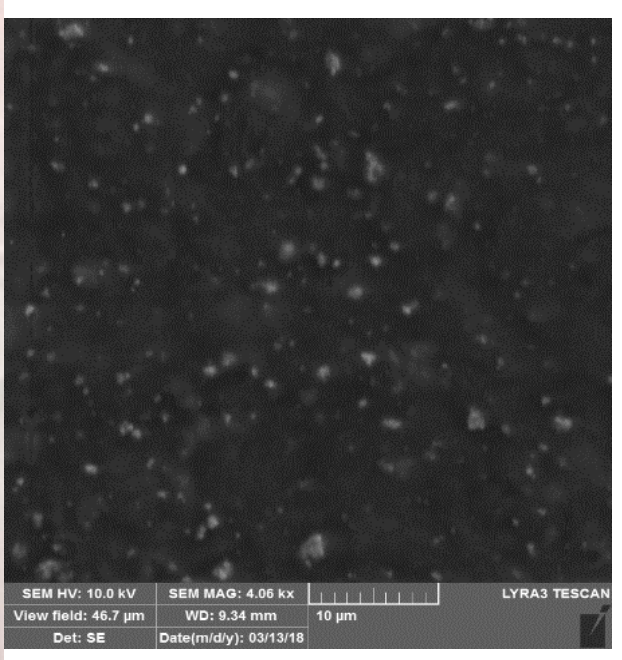

(b)

Figure 1. (a) The image of a typical 4" free-standing and flexible PEO/LAGP/Li-salt membrane, from which specimens are punched for the electrical, thermal and mechanical characterizations; (b) SEM image of the composite membranes of LAGP20.

DSC profiles of the composite membranes as well as virgin PEO and lithiated PEO films w/o LAGP are presented in Figure 2a. The heat flow is normalized to the mass of PEO. Each profile exhibits a well-defined endothermic peak in the temperature range of $40^{\circ} \mathrm{C}$ to $75^{\circ} \mathrm{C}$ corresponding to the melting transition of crystalline PEO. Apparently, adding $\mathrm{LiBF}_{4}$ or LiTFSI reduces the melting temperature $\left(\mathrm{T}_{\mathrm{m} \text {,peak }}\right)$ from $64.7^{\circ} \mathrm{C}$ to $60.7^{\circ} \mathrm{C}$ or $55.2^{\circ} \mathrm{C}$, respectivelt. It was reported that long crystalline lamellae in polymers predominantly contributes to high melting temperature [34,35]. The lower melting temperatures in the lithiated membranes suggest that the crystallite lamellae length was reduced by the presence of Li-salt, and PEO/LiTFSI electrolyte has much shorter crystallite lamellae. Further, it is determined that the crystallinities of PEO, based on the relative enthalpy of fusion values [36], are $96 \%$ in virgin $\mathrm{PEO}, 35 \%$ in $\mathrm{PEO} / \mathrm{LiBF}_{4}$, and $26 \%$ in PEO/LiTFSI. The reduced crystallite size and crystallinity synergistically reflect the interactions between PEO and lithium salts, which effectively weaken the chain intermolecular forces and simultaneously increase the segment randomness (entropy) [2]. Such interaction is much stronger in the presence of LiTFSI, compared with $\mathrm{LiBF}_{4}$. Previous studies have showed that a $\mathrm{PEO}_{\mathrm{n}} / \mathrm{LiTFSI}$ crystalline complex can be readily formed [29,33,37].

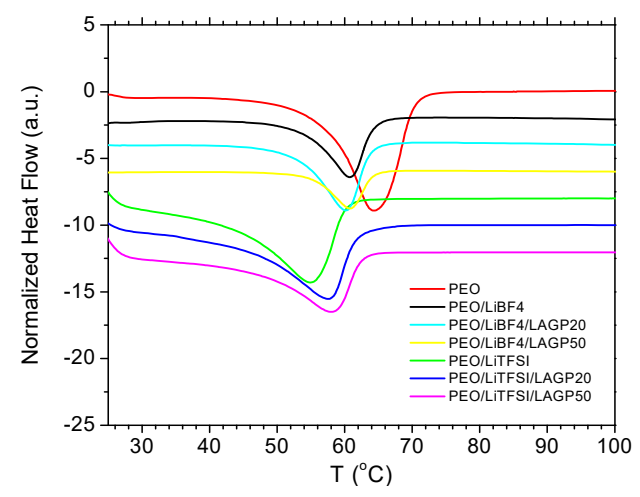

(a)

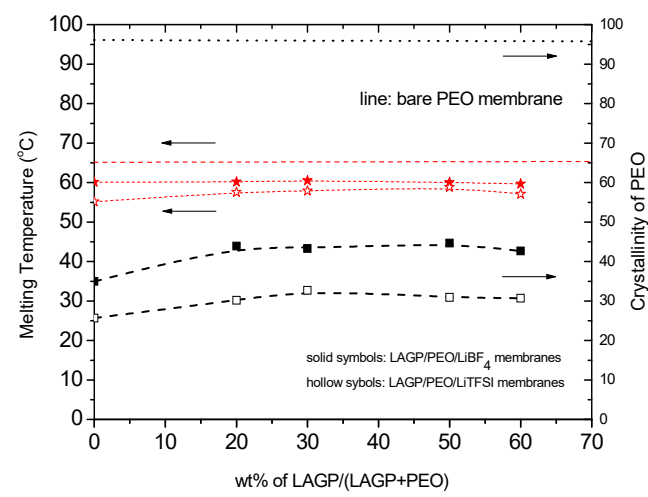

(b)

Figure 2. (a) Representative DSC profiles obtained from PEO/Li-salt/LAGP composite membranes; (b) melting temperature and PEO crystallinity as a function of LAGP content, compared with bare PEO membrane. 
The peak melting temperature and crystallinity of PEO in the lithiated PEO/LAGP composite membranes were determined in the same way. Figure $2 b$ presents the $T_{m}$,peak and crystallinity as a function of LAGP content in the two composite series. For both series, the melting temperature ascends by $2{ }^{\circ} \mathrm{C}$ upon adding $20 \mathrm{wt} \%$ LAGP ceramic particles but becomes unchanged as the LAGP content increases from $20 \mathrm{wt} \%$ to $60 \mathrm{wt} \%$. The crystallinity continuously increases upon addition of LAGP, i.e., from $35 \%$ up to $47 \%$ in $\mathrm{PEO} / \mathrm{LiBF}_{4}$ series and from $26 \%$ up to $32 \%$ in the PEO/LiTFSI series. The slight recovery of polymer crystallinity upon adding LAGP indicates that the bonding between lithium salt and polymer matrix is alleviated, which may result from the interactions between LAGP and lithium salt [38]. It is apparently, the type of lithium salt, in comparison with LAGP loading, have pronounced impacts on the thermal characteristics of the electrolyte membranes.

The impact of lithium salts on the DSC profile shape is also distinguishable. The profiles of LiTFSI-series evolve as a gradual sloping line starting around $25{ }^{\circ} \mathrm{C}$, corresponding to melting of the metastable $\mathrm{PEO}_{\mathrm{n}} / \mathrm{LiTFSI}$ crystalline phases. As temperature increases, the melting of crystalline PEO superimposes and prevails. The onset melting temperature ( $\left.\mathrm{T}_{\mathrm{m} \text {,onset }}\right)$ of PEO is $42^{\circ} \mathrm{C}$ with no LAGP and slightly increases upon adding LAGP. However, the baselines in the $\mathrm{LiBF}_{4}$-series are all horizontally flat and $\mathrm{T}_{\mathrm{m} \text {,onset }}$ remains in the vicinity of $54^{\circ} \mathrm{C}$, independent of LAGP content. The melting temperature window $\left(\Delta \mathrm{Tm}=\mathrm{T}_{\mathrm{m} \text {,peak }}-\mathrm{T}_{\mathrm{m} \text {,onset }}\right)$ is $7{ }^{\circ} \mathrm{C}$ and $13{ }^{\circ} \mathrm{C}$ for the $\mathrm{PEO} / \mathrm{LiBF}_{4}$ and $\mathrm{PEO} / \mathrm{LiTFSI}$ membranes, respectively. The narrower melting window in the $\mathrm{LiBF}_{4}$-based membranes results in rapid and close to instantaneous melting of PEO crystalline.

Figure 3a shows typical stress-strain profiles of the PEO/LAGP/ Li-salt composite membranes. As a benchmark, the profile of a virgin PEO film is presented in this figure. The average elastic modulus of the virgin PEO is $332.5 \mathrm{MPa}$, corroborated well with reported values which are in the range of 290-330 MPa depending on the molecular weight of PEO and measurement approach $[39,40]$. The virgin PEO membrane has an average yielding strength of $13.7 \mathrm{MPa}$, and it does not fracture at the maximum elongation (the instrumental limit). Adding $\mathrm{LiBF}_{4}$ into $\mathrm{PEO}$ lowered the elastic modulus and yielding strength to $230 \mathrm{MPa}$ and $12.2 \mathrm{MPa}$, respectively. However, the addition of LiTFSI into PEO resulted in drastic decrease in both the elastic moduli (23.2 MPa) and the yielding strength $(2.1 \mathrm{MPa})$. Elastic deformation in polymers takes place due to a set of segmental movements including elongation of amorphous tie chains, tiling of lamellar chain folds, separation of crystalline block, and orientation of block chains along the tensile axis. Within semicrystalline polymers, the crystalline phase, in addition to its own rigidity, ties the amorphous segments together acting as cross-links in the amorphous matrix. Consequently, the more crystalline phase the higher the elastic modulus. The much higher modulus and yielding strength in PEO/LiBF 4 than in PEO/LiTFSI are in concert with the higher PEO crystallinity in the former electrolyte.

Figure $3 \mathrm{~b}$ plots the average elastic moduli as a function of LAGP volume percentage in the two series electrolytes. Error bars were added to reflect standard deviation of the data obtained from the different specimens in each series. In the $\mathrm{LiBF}_{4}$ series, the elastic moduli increased continuously and reached $461 \mathrm{MPa}$ in the presence of $30.9 \mathrm{vol} \%$ LAGP, exceeding the value of virgin PEO. In the LiTFSI series, the average values for LAGP20 $(7.3 \mathrm{vol} \%)$ and LAGP60 (32.2 vol\%) are 60.6 MPa and 103.4 MPa, equivalent to 3-4-fold of the lithiated electrolyte with no LAGP. The increased crystallinity is one of the key factors attributing to the higher moduli in the LAGP-contained membranes. To gain insight of different ceramic loading in the presence of two different lithium salts, we compared our experimental results with the empirical/semi-empirical models proposed by Einstein (Equation (1)) and Coran (Equation (2)) [41,42]: 




(a)

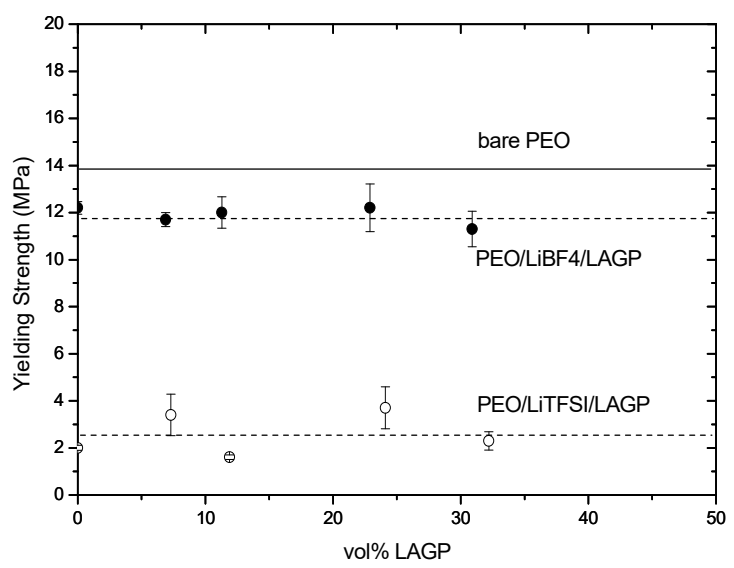

(c)

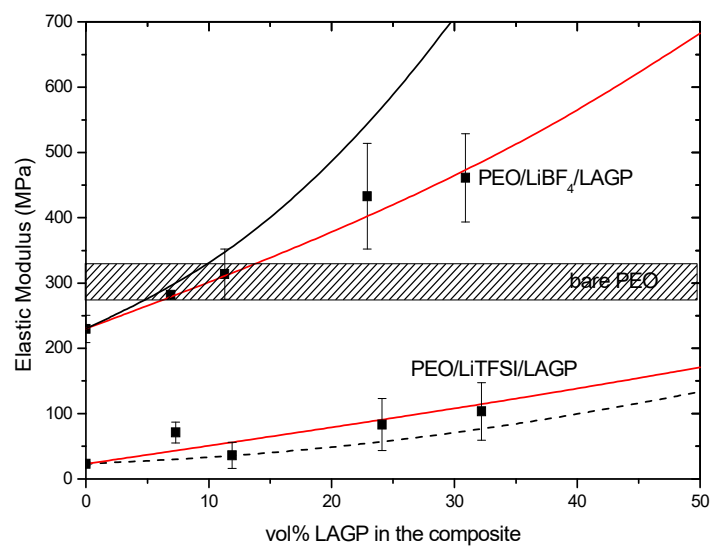

(b)

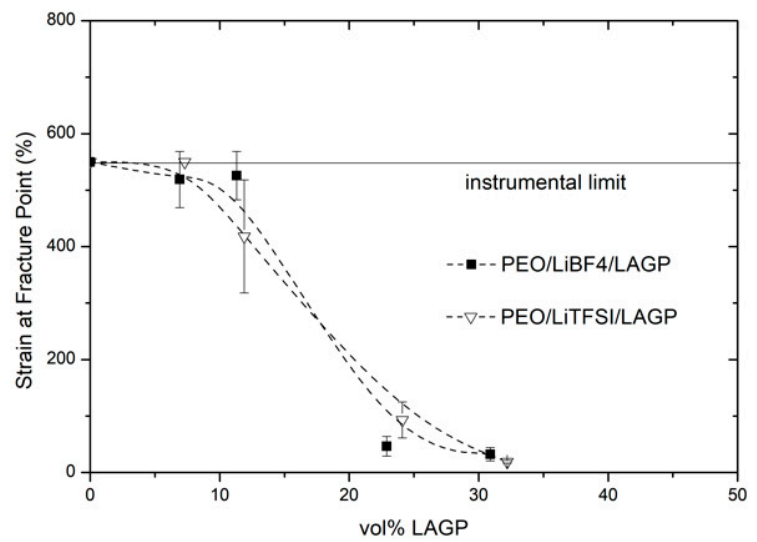

(d)

Figure 3. (a) The representative stress-strain plots obtained from lithiated electrolyte membranes with or without LAGP fillers. (b) Elastic modulus of the membranes as a function of LAGP volume percentage; symbols with error bar are experimental data, dash lines are simulated profile based on the Einstein equation, solid lines are simulated profile based on the Coran equation. (c) Yielding strength of the membranes as a function of LAGP volume percentage. (d) Strain at the fracture point of the membranes as a function of LAGP volume percentage.

$$
\begin{gathered}
\mathrm{E}_{\mathrm{c}}=\mathrm{E}_{\mathrm{m}}\left(1+2.5 \mathrm{~V}_{\mathrm{p}}+14.1 \mathrm{~V}_{\mathrm{p}}^{2}\right) \\
\mathrm{E}_{\mathrm{c}}=\mathrm{x}\left(\mathrm{E}_{\mathrm{m}} \mathrm{V}_{\mathrm{m}}+\mathrm{E}_{\mathrm{p}} \mathrm{V}_{\mathrm{p}}\right)+(1-\mathrm{x}) \frac{\mathrm{E}_{\mathrm{m}} \mathrm{E}_{\mathrm{p}}}{\mathrm{E}_{\mathrm{m}} \mathrm{V}_{\mathrm{p}}+\mathrm{E}_{\mathrm{p}} \mathrm{V}_{\mathrm{m}}}
\end{gathered}
$$

where $E_{c}, E_{m}, E_{p}$ are the moduli of composite, polymer matrix, and ceramic filler particle, $\mathrm{V}_{\mathrm{m}}$ and $\mathrm{V}_{\mathrm{p}}$ are the volume fraction of matrix and particle, respectively. In the Coran model, the parameter $\mathrm{x}$ is the portion of the upper bound relative to the lower bound of the composite. For $x=1$, the composite has a perfectly bonded filler, while $x=0$ refers to the composite with a poorly bonded filler. Seen in Figure $3 b$, the experimental results fit better with the Coran's model with $x=0.003$, independent of lithium salt. The very low value of $x$ factor suggests that the interaction between LAGP and the electrolyte matrix is weak. It has been posited that in polymer/ceramic composites a nanometer-thick interphase resulting from complex interactions between ceramic particle and polymer matrix can enhance mechanical strength [43]. However, in the present membranes made up of LAGP particles in the hundreds of nanometers with some agglomerates in micrometer scale, the contributions from the interactions within the thin interphase become less profound. 
Figure $3 c$ shows the average yielding/ultimate strength as a function of LAGP volume percentage. Different from elastic moduli, the yielding strengths of the composites appear to remain constant upon increasing the LAGP content. The strength usually relies on the effective transfer of stress between matrix and filler, which is strongly affect by the particle/matrix adhesion interaction. The results, again, imply that LAGP fillers do not alter the intrinsic interaction near bridges linking amorphous and crystalline regions.

Figure $3 \mathrm{~d}$ presents the strain-at-break, also referred to as fracture strain, as a function of LAGP content. Apparently, adding LAGP ceramics has significant impacts on the ductility/flexibility of composite membranes. The LAGP20 series do not break at elongation of $550 \%$ which is the instrumental limit. With excessive ceramic fillers, the fracture strain dramatically decreases to $318-500 \%$ for LAGP30, 30-124\% for LAGP50, and $16-44 \%$ for LAGP 60. Different from other mechanical and thermal properties, it is interesting to observe that strain-at-break appears independent of lithium salt. The volume reduction of the polymeric matrix and disruption due to the presence of ceramic particles appears dominantly attributed to the increased brittleness.

\section{Conclusions}

This study presents the impacts of lithium salts on the thermal and mechanical characteristics of the lithiated PEO doped with LAGP electrolytes. The lithium salts are dominant in terms of reducing melting temperature and enthalpy of fusion, which reflect the significant decrease in crystallite size and crystallinity of PEO. LITFSI has more profound impacts, attributed to the strong plasticizing effect of TFSI anions, than $\mathrm{LiBF}_{4}$ on reducing the crystallite size and crystallinity and, hence, the thermal melting and mechanical stiffness. Although heavily doped with ceramic filler, the increase in melting temperature and mechanical reinforcement is less profound, due to weak interactions between LAGP and PEO. It is submitted that care must be taken in the selection of lithium salt, besides tuning the ceramic filler size and loadings, in the effort of manipulating thermal and mechanical properties of the composite electrolytes for flexible or rigid applications.

Author Contributions: Conceptualization, J.L., M.R. and H.H.; methodology, J.L., M.R. and H.H.; formal analysis, J.L. and H.H.; data curation, J.L.; writing-original draft preparation, J.L. and H.H.; writing-review and editing, M.R. and H.H.; supervision, H.H.; project administration, M.R. and H.H. All authors have read and agreed to the published version of the manuscript.

Funding: This research received no external funding.

Conflicts of Interest: The authors declare no conflict of interest.

\section{References}

1. $\mathrm{Xu}, \mathrm{K}$. Electrolytes and interphases in Li-ion batteries and beyond. Chem. Rev. 2014, 114, 11503-11618. [CrossRef]

2. Sun, C.; Liu, J.; Gong, Y.; Wilkinson, D.P.; Zhang, J. Recent advances in all-solid-state rechargeable lithium batteries. Nano Energy 2017, 33, 363-386. [CrossRef]

3. Fergus, J.W. Ceramic and polymeric solid electrolytes for lithium-ion batteries. J. Power Sources 2010, 195, 4554-4569. [CrossRef]

4. Kerman, K.; Luntz, A.; Viswanathan, V.; Chiang, Y.-M.; Chen, Z. Review-Practical challenges hindering the development of solid state Li-ion batteries. J. Electrochem. Soc. 2017, 164, A1731-A1744. [CrossRef]

5. Croce Capuano, F.; Scrosati, B. Composite polymer electrolyte. J. Electrochem. Soc. 1991, 138, 1918-1922. [CrossRef]

6. Quartarone, E.; Mustarelli, P. Electrolytes for solid state lithium rechargeable batteries, recent advances and perspectives. Chem. Soc. Rev. 2011, 40, 2525-2540. [CrossRef] [PubMed]

7. Zhao, Y.; Huang, Z.; Chen, S.; Chen, B.; Yang, J.; Zhang, Q.; Ding, F.; Chen, Y.; Xu, X. A promising PEO/LAGP hybrid electrolyte prepared by a simple method for all-solid-state lithium batteries. Solid State Ion. 2016, 295, 65-71. [CrossRef]

8. Zhao, Y.; Wu, C.; Peng, G.; Chen, X.; Yao, X.; Bai, Y.; Wu, F.; Chen, S.; Xu, X. A new solid polymer electrolyte incorporating $\mathrm{Li}_{10} \mathrm{GeP}_{2} \mathrm{~S}_{12}$ into a polyethylene oxide matrix for all-solid-state lithium batteries. J. Power Sources 2016, 301, 47-53. [CrossRef]

9. Chen, L.; Li, Y.; Li, S.P.; Fan, L.Z.; Nan, C.W.; Goodenough, J.B. PEO/garnet composite electrolytes for solid-state lithium batteries: From 'ceramic-in-polymer' to 'polymer-in-ceramic'. Nano Energy 2018, 46, 176-184. [CrossRef]

10. Wang, W.; Yi, E.; Fici, A.J.; Laine, R.M.; Kieffer, J. Lithium ion conducting poly(ethylene oxide)-based solid electrolytes containing active or passive ceramic nanoparticles. J. Phys. Chem. C 2017, 121, 2563-2573. [CrossRef] 
11. Choi, J.H.; Lee, C.H.; Yu, J.H.; Doh, C.H.; Lee, S.M. Enhancement of ionic conductivity of composite membranes for all-solid-state lithium rechargeable batteries incorporating tetragonal $\mathrm{Li}_{7} \mathrm{La}_{3} \mathrm{Zr}_{2} \mathrm{O}_{12}$ into a polyethylene oxide matrix. J. Power Sources 2015, 274, 458-463. [CrossRef]

12. Masoud, E.M.; El-Bellihi, A.A.; Bayoumy, W.A.; Mousa, M.A. Organic-inorganic composite polymer electrolyte based on PEO$\mathrm{LiClO}_{4}$ and nano- $\mathrm{Al}_{2} \mathrm{O}_{3}$ filler for lithium polymer batteries: Dielectric and transport properties. J. Alloys Comp. 2013, 575, 223-228. [CrossRef]

13. Lee, L.; Park, S.; Kim, S. Effect of nano-sized barium titanate addition on PEO/PVDF blend-based composite polymer electrolytes. Solid State Ion. 2013, 234, 19-24. [CrossRef]

14. Capiglia, C.; Mustarelli, P.; Quartarone, E.; Tomasi, C.; Magistris, A. Effects of nanoscale $\mathrm{SiO}_{2}$ on the thermal and transport properties 2 of solvent-free, poly(ethylene oxide) (PEO)-based polymer electrolytes. Solid State Ion. 1999, 118, 73-79. [CrossRef]

15. Jeon, J.; Kim, M.; Kwak, S. Effects of addition of $\mathrm{TiO}_{2}$ nanoparticles on mechanical properties and ionic conductivity of solvent-free polymer electrolytes based on porous P (VdF-HFP)/P (EO-EC) membranes. J. Power Sources 2006, 162, 1304-1311. [CrossRef]

16. Kumar, B.; Scanlon, L.; Marsh, R.; Mason, R.; Higgins, R.; Baldwin, R. Structural evolution and conductivity of PEO:LiBF $4-\mathrm{MgO}$ composite electrolytes. Electrochim. Acta 2001, 46, 1515-1521. [CrossRef]

17. Angulakshmi, N.; Jijeesh, K.S.N.; Nair, R.; Gerbaldi, C.; Bongiovanni, R.; Penazzi, N.; Stephan, A.M. Cycling profile of $\mathrm{MgAl}_{2} \mathrm{O}_{4}-$ incorporated composite electrolytes composed of $\mathrm{PEO}$ and $\mathrm{LiPF}_{6}$ for lithium polymer batteries. Electrochim. Acta 2013, 90, 179-185. [CrossRef]

18. Nagajothi, A.J.; Kannan, R.; Rajashabala, S. Electrochemical performance of plasticized PEO-LiTf complex-based composite gel polymer electrolytes with the addition of barium titanate. Ionics 2018, 24, 1407-1414. [CrossRef]

19. Wang, X.; Zhang, Y.; Zhang, X.; Liu, T.; Lin, Y.-H.; Li, L.; Shen, Y.; Nan, C.-W. Lithium-Salt-Rich PEO/Li ${ }_{0.3} \mathrm{La}_{0.557} \mathrm{TiO}_{3} \mathrm{Interpene-}$ trating Composite Electrolyte with Tree-Dimensional Ceramic Nano-Backbone for All-Solid-State Lithium-ion Batteries. ACS Appl. Mater. Interfaces 2018, 10, 24791-24798. [CrossRef] [PubMed]

20. Younesi, R.; Veith, G.M.; Johansson, P.; Edstro, K.; Vegge, T. Lithium salts for advanced lithium batteries: Li-metal, Li-O 2 , and Li-S. Energy Environ. Sci. 2015, 8, 1905. [CrossRef]

21. Gnanaraj, J.S.; Zinigrad, E.; Asraf, L.; Gottlieb, H.E.; Sprecher, M.; Aurbach, D.; Schmidt, M. The use of accelerating rate calorimetry (ARC) for the study of the thermal reactions of Li-ion battery electrolyte solutions. J. Power Sources 2003, 119, 794-798. [CrossRef]

22. Ping, P.; Wang, Q.; Sun, J.; Xiang, H.; Chen, C. Thermal Stabilities of Some Lithium Salts and Their Electrolyte Solutions with and Without Contact to a $\mathrm{LiFePO}_{4}$ Electrode. J. Electrochem. Soc. 2010, 157, A1170. [CrossRef]

23. Zhang, S.S.; Xu, K.; Jow, T.R. Study of $\mathrm{LiBF}_{4}$ as an electrolyte salt for a Li-Ion battery. J. Electrochem. Soc. 2002, 149, A586. [CrossRef]

24. Zhang, S.S.; Xu, K.; Jow, T.R. A new approach toward improved low temperature performance of Li-ion battery. Electrochem. Commun. 2002, 4, 928-932. [CrossRef]

25. Steudte, S.; Neumann, J.; Bottin-Weber, U.; Diedenhofen, M.; Arning, J.; Stepnowski, P.; Stolte, S. Hydrolysis study of fluoroorganic and cyano-based ionic liquid anions-Consequences for operational safety and environmental stability. Green Chem. 2012, 14, 2474 [CrossRef]

26. Thokchom, J.S.; Gupta, N.; Kumar, B. Superionic conductivity in a lithium aluminum germanium phosphate glass-ceramic. J. Electrochem. Soc. 2008, 155, A915-A920. [CrossRef]

27. Kumar, B.; Kumar, J.; Leese, R.; Fellner, J.P.; Rodrigues, S.J.; Abraham, K.M. A solid state rechargeable long cycle life lithium-air battery. J. Electrochem. Soc. 2010, 157, A50-A54. [CrossRef]

28. Robinson, J.P.; Kichambare, P.D.; Deiner, J.L.; Miller, R.; Rottmayer, M.A.; Koenig, G.M., Jr. High temperature electrode-electrolyte interface formation between $\mathrm{LiMn}_{1.5} \mathrm{Ni}_{0.5} \mathrm{O}_{4}$ and $\mathrm{Li}_{1.4} \mathrm{Al}_{0.4} \mathrm{Ge}_{1.6}\left(\mathrm{PO}_{4}\right)_{3}$. J. Am. Ceram. Soc. 2018, 101, 1087-1094. [CrossRef]

29. Lee, J.; Howell, T.; Rottmayer, M.; Boeckl, J.; Huang, H. Free-standing LAGP/PEO/LiTFSI composite electrolyte memebranes for applications to flexible solid state lithium-based batteries. J. Electrochem. Soc. 2019, 166, A416-A422. [CrossRef]

30. Sircar, A.K.; Weissman, P.T.; Kumar, B.; Marsh, R.A. Evaluation of doped polyethylene oxide as solid electrolyte. Thermochim. Acta 1993, 226, 281-299. [CrossRef]

31. Pzyczka, K.; Marzantowicz, M.; Dygas, J.R.; Krok, F. Ionic conductivity and lithium transference number of poly(ethylene oxide): LiTFSI system. Electrochim. Acta 2017, 227, 127-135. [CrossRef]

32. Wen, S.J.; Richardson, T.J.; Ghantous, D.I.; Striebel, K.A.; Ross, P.N.; Cairns, E.J. FTIR characterization of $\left.\mathrm{PEO}^{2} \mathrm{LiN}_{(\mathrm{CF}} \mathrm{SO}_{2}\right)_{2}$ electrolytes. J. Electroanal. Chem. 1996, 408, 113-118. [CrossRef]

33. Lee, J. Fabrication and Characterizations of LAGP/PEO Composite Electrolytes for All Solid-State Lithium-Ion Batteries. Master's Thesis, Wright State University, Dayton, OH, USA, 2018.

34. Farrow, G. Crystallinity, 'crystallite size' and melting point of polypropylene. Polymer 1963, 4, 191-197. [CrossRef]

35. Jeong, H.; Chowdhury, M.; Wang, Y.; Sezen-Edmonds, M.; Loo, Y.-L.; Register, R.A.; Arnold, C.B.; Priestley, R.D. Tuning morphology and melting temperature in polyethylene films by MAPLE. Macromolecules 2018, 51, 512-519. [CrossRef]

36. Kong, Y.; Hay, J.N. The enthalpy of fusion and degree of crystallinity of polymers as measured by DSC. Eur. Polym. J. 2003, 39, 1721-1727. [CrossRef]

37. Gorecki, W.; Jeannin, M.; Belorizky, E.; Roux, C.; Armand, M. Physical properties of solid electrolyte PEO(LiTFSI) complexes. J. Phys. Condens. Matter 1995, 7, 6823-6832. [CrossRef] 
38. Yu, T.; Han, Y.; Wang, H.; Xiong, S.; Xie, K.; Guo, Q. Preparation and lithium ion transport behavior for $\mathrm{Li}_{1.5} \mathrm{Al}_{0.5} \mathrm{Ge}_{1.5}\left(\mathrm{PO}_{4}\right)_{3}$ based solid composite electrolyte. Chem. J. Chin. Univ. 2016, 37, 306-315.

39. Nie, H.; Motomatsu, M.; Mizutani, W.; Tokumoto, H. Local elasticity measurement on polymers using atomic force microscopy. Thin Solid Films 1996, 273, 143-148. [CrossRef]

40. Lee, A.; Lee, H.; Lee, Y.; Lee, M. Determination of the elastic modulus of poly(ethylene oxide) using a photoisomerizing dye. Chem. Phys. 2013, 422, 246-250.

41. Fu, S.Y.; Feng, X.Q.; Lauke, B.; Mai, Y.W. Effects of particle size, particle/matrix interface adhesion and particle loading on mechanical properties of particulate-polymer composites. Compos. B 2008, 39, 933-961. [CrossRef]

42. Ahmed, A.; Jones, F.R. A review of particulate re-enforcement theories for polymer composites. J. Mater. Sci. 1990, $25,4933-4942$. [CrossRef]

43. Deng, F.; van Vliet, K.J. Prediction of elastic properties for polymer-particle nanocomposites exhibiting an interphase. Nanotechnology 2011, 22, 165703. [CrossRef] [PubMed] 